\title{
Optimal AVR Control System using Particle Swarm Optimization
}

\author{
Ahmed J. Sultan \\ Department of Electrical Power Engineering Techniques, Electrical Engineering Technical College, \\ Middle Technical University, Baghdad, Iraq
}

\begin{abstract}
This paper proposed a PSO with the constriction factor algorithm was used to tune PID-gains for an automatic voltage regulator (AVR) system. In the proposed approach, optimal tuning of PID-gains has very significant issue to perform the target value. Thus, a proposed algorithm has been used to get a better performance. The superiority of the PSO-PID controller is demonstrated through comparing the results with other techniques like Ziegler-Nichols method. Numerical results reveal that the PSO-PID controller has better dynamic response, fast convergence, and highquality-solution than the other approaches based on rise and settling time of terminal voltage signal of generator.
\end{abstract}

Keywords: AVR system, PID-controller, PSO, constriction factor.

\section{INTRODUCTION}

Recently, the scale of the power grid has been expanded of Sensor. The schematic diagram is demonstrated in fast and complex to satisfy the increasing of the load figure (1) [6].

demand with in nominal voltage. AVR system is used to improve power system equality over maintain the terminal voltage with in permit level. It has ineffectual dynamic response, so that to overcome this problem it will be insert in closed-loop with the controller [1].

Presently, many controllers can be used for AVR system. Among them, the PID-controller is simple structure and efficient performance in the industry process [2]. PID consists of three parameters: proportional, integral, and derivative gains which are to be tuning satisfactory. A numerous algorithms were used to set these parameters properly such as Evolutionary-algorithms, Fuzzy-LogicSystem, and Neural-Network ... etc. In [3] the authors proposed a PSO-PID for AVR system. The new fitness function was used to find optimality of PID-gains. In [4] the authors present a new hybrid algorithm consists of PSO and the Gravitational Search algorithm (PSOGSA) to obtain optimal values of PID-gains for AVR system. In [5] the authors present a teaching-learning based optimization algorithm (TLBO) for AVR system to get good performance and it was executed in MATLAB environment.

In this paper, a PSO with the constriction factor algorithm was proposed to set the PID-gains in the AVR system. A new objective function was used to achieve better dynamic response than the common performance indices firstly. And it's compared with conventional $\mathrm{ZN}$-algorithm to emphasize effectiveness of the proposed-algorithm.

\section{MODELLING OF THE AVR SYSTEM}

A linearized model of AVR system is consists of four parts: Amplifier, Exciter, and Generator with the feedback

- Amplifier:

$$
\frac{V_{R}(s)}{V_{E(s)}}=\frac{K_{A}}{1+\tau_{A} S}(1)
$$

- Exciter:

$$
\begin{aligned}
& \frac{V_{F}(s)}{V_{R}(s)}=\frac{K_{E}}{1+\tau_{E} S}(2) \\
& \frac{V_{t}(s)}{V_{F}(s)}=\frac{K_{G}}{1+\tau_{G} S}(3)
\end{aligned}
$$

- Generator:

- Sensor:

$$
\frac{V_{S}(s)}{V_{t}(s)}=\frac{K_{R}}{1+\tau_{R} S}(4)
$$

The transfer function of system is:

$$
\frac{\Delta \mathrm{V}_{\mathrm{t}(\mathrm{s})}}{\Delta \mathrm{V}_{\text {ref }(\mathrm{s})}}=\frac{0.1 \mathrm{~S}+10}{0.0004 \mathrm{~S}^{4}+0.045 \mathrm{~S}^{3}+0.555 \mathrm{~S}^{2}+1.51 \mathrm{~S}+11}
$$

Where:

$\mathrm{K}_{\mathrm{A}} \quad$ Amplifier gain

$\tau_{\mathrm{A}} \quad$ Amplifier time constant

$\mathrm{K}_{\mathrm{E}} \quad$ Exciter gain

$\tau_{\mathrm{E}} \quad$ Exciter time constant

$\mathrm{K}_{\mathrm{G}} \quad$ Generator gain

$\tau_{\mathrm{G}} \quad$ Generator time constant

$K_{R} \quad$ Sensor gain

$\tau_{\mathrm{R}} \quad$ Sensor time constant

Figure (2) illustrate the step terminal voltage response. It is obviously that is oscillatory stable and has a rise and settling time are $(0.264,6.985)$ respectively. 
Vol. 6, Issue 1, January 2017

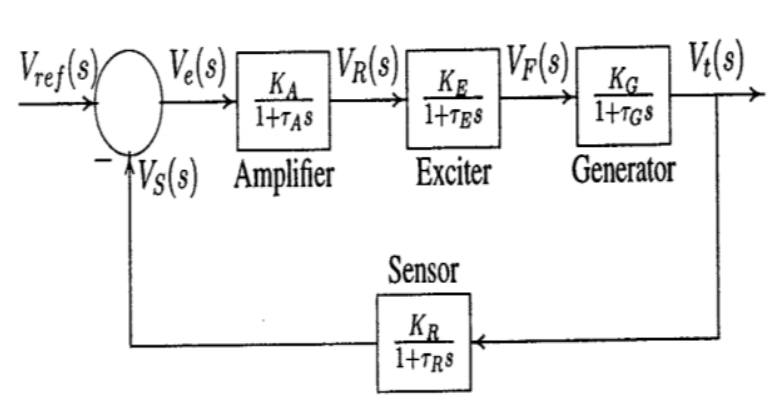

Figure (1) Linearized AVR system block diagram [6]

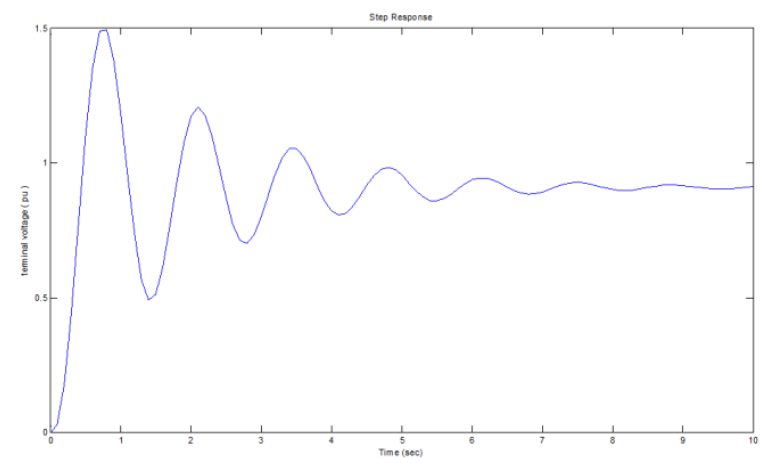

Figure (2) AVR system step terminal voltage response

Therefore, to enhance the dynamic response of system a PID-controller insert to the cooled-loop as shown in figure (3) and the transfer function of system will become:

$$
\begin{gathered}
\frac{\Delta V_{t(s)}}{\Delta V_{\text {ref }(s)}}= \\
\frac{0.1 K_{d} S^{3}+\left(0.1 K_{p}+10 K_{d}\right) S^{2}+\left(0.1 K_{i}+10 K_{p}\right) S+10 K_{i}}{0.0004 S^{5}+0.045 S^{4}+0.555 S^{3}+\left(1.51+10 K_{d}\right) S^{2}+\left(1+10 K_{p}\right) S+11}(6)
\end{gathered}
$$

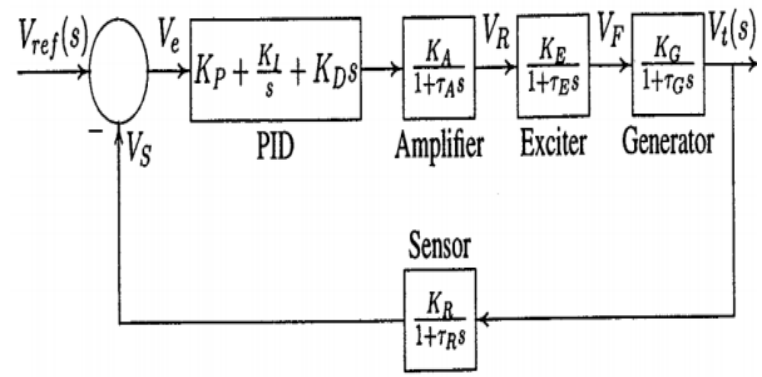

Figure (3) AVR-PID system [6]

\section{III.PARTICLE SWARM OPTIMIZATION}

The one of the swarm intelligent techniques is PSOalgorithm which developed by Eberhart and Kennedy depend on the simulation of bird flocking and fish pool [7]. It is randomly initialization of particles in Ddimension search space. The initial position and velocity is taken as the best one for start point of algorithm then the particles are updated the velocity and position according the following equations:

$$
\begin{gathered}
V_{i}^{k+1}=W V_{i}^{k}+C_{1} R_{1} *\left(P_{\text {best }}-X_{i}^{k}\right)+C_{2} R_{2} *\left(g_{\text {best }}-\right. \\
\left.X_{i}^{k}\right)(7)
\end{gathered}
$$

$$
X_{i}^{k+1}=X_{i}^{k}+V_{i}^{k+1}
$$

Where:

$V_{i}^{k} \quad$ Velocity of particle I of iteration k.

$\mathrm{W} \quad$ Inertia weighting factor.

$R_{1}, R_{2} \quad$ Random number between 0 and 1 .

$C_{1}, C_{2} \quad$ Acceleration constant.

$X_{i}^{k} \quad$ Current searching point.

$X_{i}^{k+1} \quad$ Modified searching point.

$P_{\text {best }} \quad$ Best position of the $\mathrm{i}^{\text {th }}$ particle.

$g_{\text {best }}$ The index of best particle among the entire

\begin{tabular}{|c|c|c|}
\hline \# & Name of inertia weight & Formula of inertia weight \\
\hline 1. & Constant inertia weight & $W=$ constant \\
\hline 2. & Random inertia weight & $W=0.5+\frac{\text { Rand }()}{2}$ \\
\hline 3. & Adaptive inertia weight & $\begin{array}{c}W_{i}(t+1)=W(0)+\left(W\left(n_{t}\right)-W(0)\right) \frac{e^{m_{i}(t)}-1}{e^{m_{i}(t)}+1} \\
m_{i}(t)=\frac{\text { gbest }- \text { current }}{\text { gbest }+ \text { current }}\end{array}$ \\
\hline 4. & Sigmoid increasing inertia weight & $\begin{array}{c}W_{k}=\frac{\left(W_{\text {start }}-W_{\text {end }}\right)}{\left(1+e^{u *(k-n * g e n)}\right)}+W_{\text {end }} \\
u=10^{(\log (g e n)-2)}\end{array}$ \\
\hline 5. & Sigmoid decreasing inertia weight & $\begin{array}{c}W_{k}=\frac{\left(W_{\text {start }}-W_{\text {end }}\right)}{\left(1+e^{-u *(k-n * g e n)}\right)}+W_{\text {end }} \\
u=10^{(\log (g e n)-2)}\end{array}$ \\
\hline 6. & Linear decreasing inertia weight & $W_{k}=W_{\max }-\frac{W_{\max }-W_{\min }}{\text { maxiter }} \times K$ \\
\hline 7. & The chaotic inertia weight & $\begin{array}{c}w=\left(w_{1}-w_{2}\right) x \frac{\text { Maxiter }- \text { iter }}{\text { Maxiter }}+w_{2} x z \\
z=4 x z x(1-z)\end{array}$ \\
\hline 8. & Chaotic random inertia weight & $\begin{array}{c}w=0.5 x \text { rand }(\overline{1})+0.5 x z \\
z=4 \times z x(1-z)\end{array}$ \\
\hline 9. & Oscillating inertia weight & $\begin{array}{c}w(t)=\frac{W_{\min }+W_{\max }}{2}+\frac{W_{\max }-W_{\min }}{2 S_{1}} \cos \left(\frac{2 \pi t}{T}\right) \\
T=\frac{2 S_{1}}{3+2 k}\end{array}$ \\
\hline 10. & Global-local best inertia weight & $w_{i}=\left(1.1-\frac{\text { gbeat }_{i}}{\left(\text { pbest }_{i}\right)}\right)$ \\
\hline 11. & Simulated annealing inertia weight & $w_{k}=w_{\min }+\left(w_{\max }-w_{\min }\right) x \lambda^{(k-1)}$ \\
\hline 12. & $\begin{array}{l}\text { Natural exponent inertia weight } \\
\text { (e1) }\end{array}$ & $\left.w(t)=w_{\min }+\left(w_{\max }-w_{\min }\right) \cdot e^{-\left[\frac{t}{\frac{1}{\text { Maxiter }}}\right]}\right)$ \\
\hline 13. & $\begin{array}{l}\text { Natural exponent inertia weight } \\
\text { (e2) }\end{array}$ & $\left.w(t)=w_{\min }+\left(w_{\max }-w_{\min }\right) \cdot e^{-\left[\frac{t}{\text { Maxiter }}\right]^{2}}\right)$ \\
\hline 14. & $\begin{array}{l}\text { Logarithm decreasing inertia } \\
\text { weight }\end{array}$ & $w=w_{\max }+\left(w_{\min }-w_{\max }\right) x \log _{10}\left(a+\frac{10 t}{T_{\max }}\right)$ \\
\hline 15. & Exponent decreasing inertia weight & $w=\left(w_{\max }-w_{\min }-d_{1}\right) \cdot e^{\left(\frac{1}{1+\frac{d_{2} t}{t_{\max }}}\right)}$ \\
\hline
\end{tabular}
particle in the population.

The 15th different strategies of inertia weight which modified the algorithm to enhance the convergence of algorithm as listed in Table (1) [8].

Table (1) Different Inertia Weight

Newly, the constriction factor was used to ensure of algorithm according to the following [9]:

$$
\begin{gathered}
V_{i}^{k+1}=K\left[V_{i}^{k}+C_{1} R_{1} *\left(P_{\text {best }}-X_{i}^{k}\right)+C_{2} R_{2} *\right. \\
\left.\left(g_{\text {best }}-X_{i}^{k}\right)\right](9) \\
K=\frac{2}{\left|2-\varphi-\sqrt{\varphi^{2}-4 \varphi}\right|}
\end{gathered}
$$

Where:

$\varphi=C_{1}+C_{2}$ and $\varphi>4$

The PSO-algorithm with the constriction factor has efficient and high-quality-solution than traditional PSOalgorithm [9]. 
Vol. 6, Issue 1, January 2017

\section{IV.OPTIMAL CONTROL DESIGN OF AVR SYSTEM}

The schematic diagram of the proposed-controller is illustrated in figure (3).

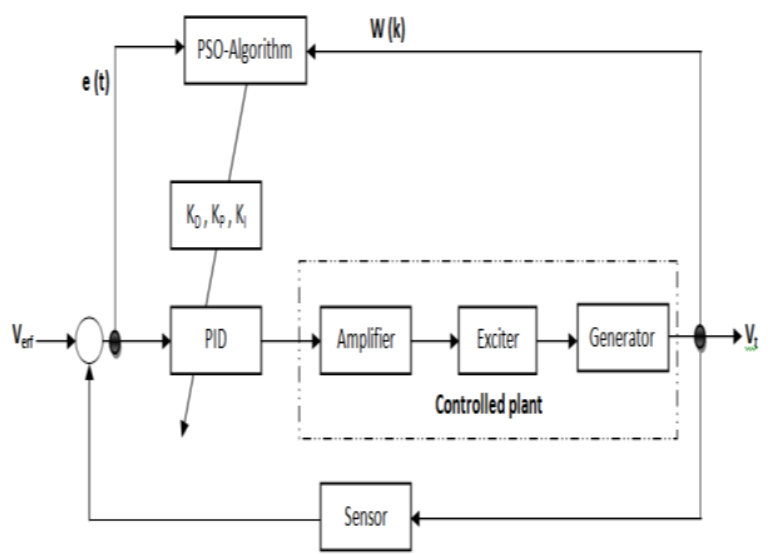

Figure (4) block diagram of PSO-PID

The performance algorithm depended on the objective function that be used. The common performance indices are listed in table (2) [10], minimization of objectivefunction is chosed according to:

Table (2) Mathematical description of different performance criteria

\begin{tabular}{|c|c|c|}
\hline Performance Criteria & Symbol & $\begin{array}{c}\text { Mathematical description of the } \\
\text { error }\end{array}$ \\
\hline $\begin{array}{c}\text { Integral of Absolute Magnitude } \\
\text { of the Error }\end{array}$ & IAE & $J_{\text {IAE }}=\int_{0}^{T}|e(t)| d t$ \\
\hline $\begin{array}{c}\text { Integral of the Square of the } \\
\text { Error }\end{array}$ & ISE & $J_{I S E}=\int_{0}^{T} e^{2}(t) d t$ \\
\hline $\begin{array}{c}\text { Integral of Time multiplied by } \\
\text { Square Error }\end{array}$ & ITSE & $J_{\text {ITSE }}=\int_{0}^{T} t \cdot e^{2} d t$ \\
\hline
\end{tabular}

$$
\text { objective function }=\frac{1}{J}
$$

To improve the controller, a modification in the objectivefunction is requested. In [3], the performance index was described as follow:

$$
W(k)=\left(1-e^{-\beta}\right)\left(M_{p}+e_{s s}\right)+e^{-\beta}\left(t_{s}-t_{r}\right)
$$

And

$$
\text { objective function }=\frac{1}{W_{(k)} \times J}(13)
$$

Where:

$\begin{array}{cl}W(k) & \text { Performance function. } \\ \mathrm{K} & {[\mathrm{Kp}, \mathrm{Ki}, \mathrm{Kd}] .} \\ \beta & \text { weighting factor } \\ M_{p} & \text { Maximum overshoot. } \\ e_{s s} & \text { Steady stat error. }\end{array}$

$t_{s} \quad$ Settling time.

$t_{r} \quad$ Rise time.

Equation 13 can be improving the dynamic response and boost the accuracy and efficiency of the controller when $\beta$ $=1.5$ that be determined experimentally. The PSO-PIDcontroller flow-chart is shown in figure (4).

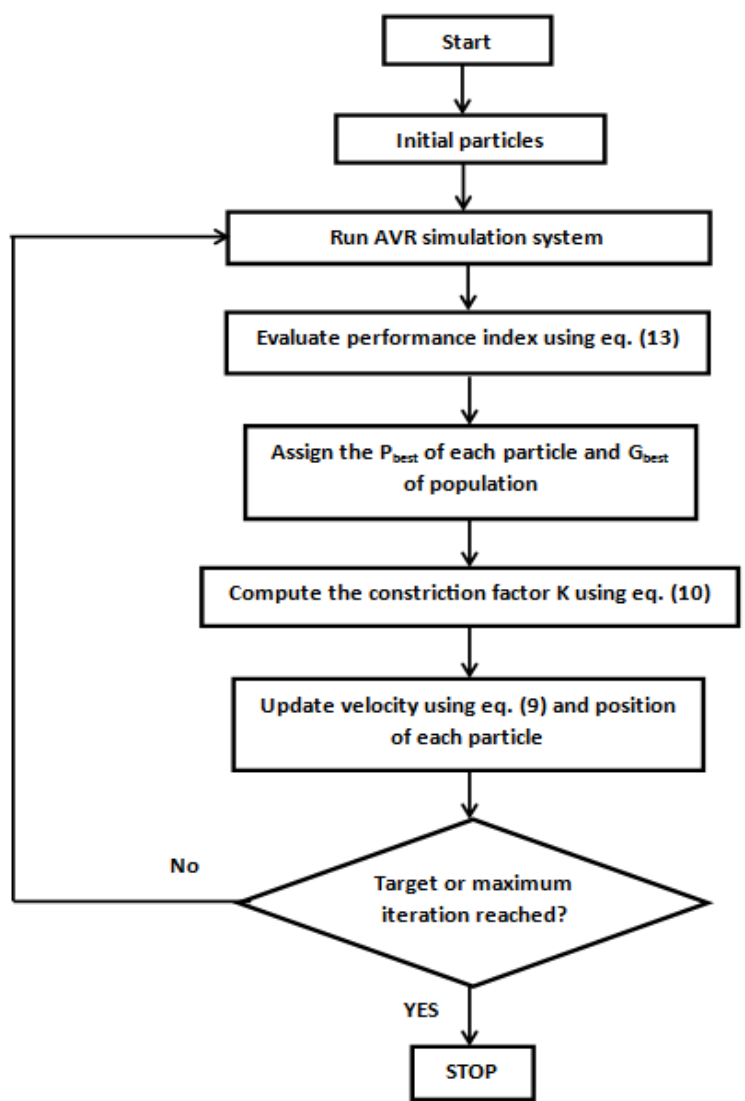

Figure (5) Flow-chart of the proposed algorithm

\section{SIMULATION RESULTS}

The AVR system structure and its performance of step response was shown in figures $(1,2)$ respectively. The nominal parameters values are given in appendix $\mathrm{A}$ and

\begin{tabular}{|c|c|c|}
\hline \multicolumn{2}{|l|}{ Parameters } & Value \\
\hline \multicolumn{2}{|l|}{ Population size } & 80 \\
\hline \multicolumn{2}{|l|}{ Maximum iteration } & 100 \\
\hline \multirow{2}{*}{ Acceleration factors } & $\mathrm{C}_{1}$ & 2.5 \\
\hline & $\mathrm{C}_{2}$ & 2.9 \\
\hline \multicolumn{2}{|c|}{ Search space of each particle } & $0-1$ \\
\hline
\end{tabular}
the proposed-algorithm parameters are given in table (3).

Table (3) The parameters of proposed-algorithm

The simulation results demonstrated in figure (6) is carried out using common performance-indices and new objective-function in eq. (13). That showed ITSE performance index has a better dynamic response than the other performance-indices. 
Vol. 6, Issue 1, January 2017

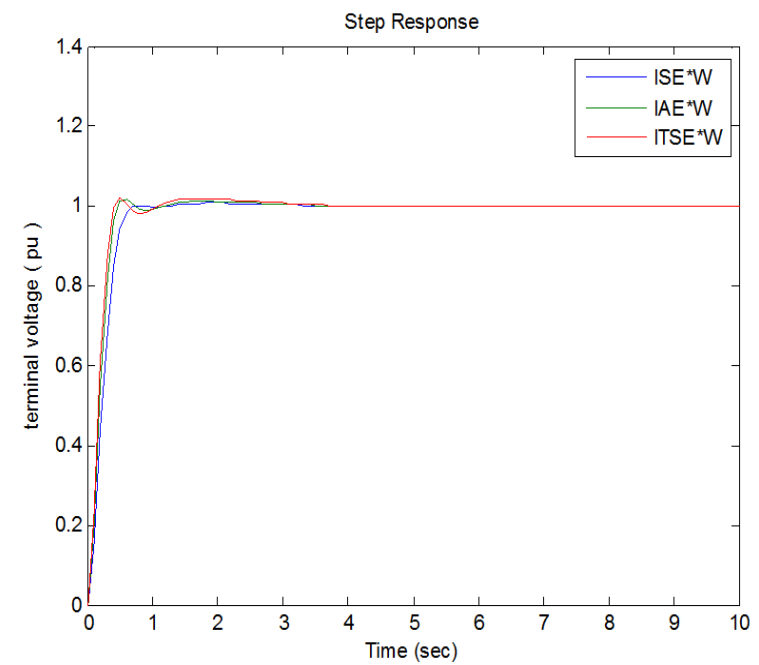

Figure (6) step response of AVR system using objective function using eq. (13)

Table (4) Comparing between $\mathrm{ZN}$ and proposed controller

\begin{tabular}{|c|c|c|c|c|c|}
\hline Controller & $K_{P}$ & $K_{D}$ & $K_{I}$ & Rise time (sec) & Settling time (sec) \\
\hline ZN-PID & 1.08 & 0.1469 & 1.98 & 0.232 & 2.95 \\
\hline PSO-PID & 0.6841 & 0.2679 & 0.6186 & 0.276 & 0.3761 \\
\hline
\end{tabular}

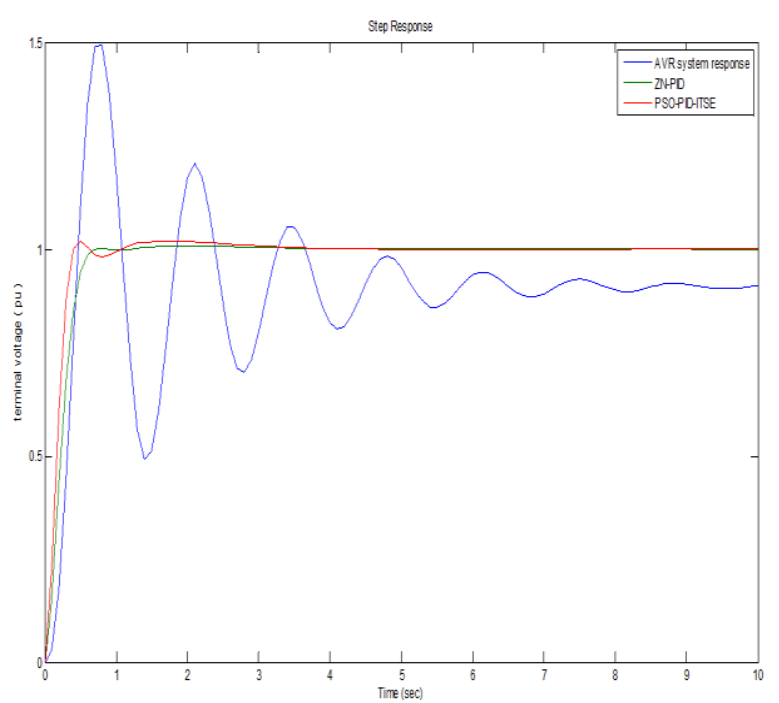

Figure (7) Voltage step response of AVR system

Table (5) Comparison of different schema controls

\begin{tabular}{|c|c|c|c|c|c|}
\hline Controller & $K_{P}$ & $K_{D}$ & $K_{1}$ & Rise time $(s e c)$ & Settling time (sec) \\
\cline { 2 - 6 } & 0.4008 & 0.1017 & 0.2556 & 0.559 & 0.8296 \\
\hline TLBO-PID [5] & 0.4783 & 0.1411 & 0.3420 & 0.431 & 0.691 \\
\hline PSOGSA-PID [4] & 0.45 & 0.564 \\
\hline APSO-PID [11] & 0.5536 & 0.1940 & 0.4369 & 0.346 & 0.43 \\
\hline GA-PID [3] & 0.6193 & 0.2228 & 0.4589 & 0.3 & 0.42 \\
\hline PSO-PID [3] & 0.63 & 0.2276 & 0.4538 & 0.3 & 0.3761 \\
\hline PSO-PID & 0.6841 & 0.2679 & 0.6186 & 0.276 & \\
\hline
\end{tabular}

The different schema controls were used by the researches as listed in table (5) which seem the efficiency and robustness of the controller to return the terminal voltage of generator to its permit value with lowest rise time and shortest settling time.

\section{VI.CONCLUSION}

In this paper, a modify PSO-algorithm with new objective function have been successfully proposed for AVR system dynamic response improvement. The constriction factor helped the PSO-algorithm to converge fastly and accurately to the best point. Through the results, the PSOPID controller can perform an efficient and precise approach to reach the optimal PID-gains compared to the other methods.

\section{REFERENCES}

[1] Kundur P., Power system stability and control, McGraw-Hill, 1994.

[2] Ajit K. Mandal, introduction to control engineering: modeling, analysis, design, $2^{\text {nd }}$ ed., New Age International, 2012.

[3] Ching-Chang W., Shih-An L., Hou-Yi W., optimal PID controller design for AVR system, Tamkang journal of science and engineering, Vol.12, No.3, 2009.

[4] Supol K. and Wudhichai A., optimization of PID controller based on PSOGSA for an automatic voltage regulator system, Procedia Computer Science Vol. 86, P.p. 87-90, Elsevier 2016.

[5] Mohammed J. H. M., Mehdi B., Saber A. N., Mehdi G. M., Design optimization of PID in automatic voltage regulator system using teaching-learning based optimization algorithm, International journal of power and energy conversion, Vol.7, No.4, 2016.

[6] Saadat H., Power system analysis (McGraw-Hill; 1999).

[7] J. Kennedy and R. C. E., Swarm Intelligence (2nd ed., Morgan Kaufmann, 2001).

[8] J. C. Bansal, P. K. Singh, M. Saraswat, A. Verma, Sh. S. Jadon, A. Abraham, Inertia weight strategies in particle swarm optimization, $3^{\text {rd }}$ IEEE conference on Nature and Biologically Inspired Computing (NABIC), Spain, 2011.

[9] R.C. Eberhart, Y. Shi, Comparing inertia weight and constriction factors in particle swarm optimization, proc. Of congress on Evolutionary Computation (CEC), IEEE, 2000.

[10] L. J., PID controller tuning using evolutionary programming, conference On American control, VA, 2001.

[11] J. F. Nirmal, D. J. Auxillia, Adaptive PSO based tuning of PID controller for an automatic voltage regulator system, International conference on circuits, power and computing technologies (ICCPCT), IEEE 2013.

\section{APPENDIX}

The nominal parameter values of AVR system are:

$$
\begin{aligned}
K_{A} & =10 \\
\tau_{A} & =0.1 \\
K_{E} & =1 \\
\tau_{E} & =0.4 \\
K_{G} & =1 \\
\tau_{G} & =1 \\
K_{R} & =1 \\
\tau_{R} & =0.05
\end{aligned}
$$

